\title{
Spontaneous Diabetes in Laboratory Animals
}

\author{
Introduction by Workshop Editors
}

Key-words: Spontaneous Diabetes, Diabetes in animals, Genes for diabetes, Mutations for diabetes, Obesity, Genotypes.

Diabetes mellitus has occurred in man at least as long as written medical records exist; approximately 4000 years. It has also been found in all human societies where any consistent search has been made. The same is true of animals, particularly those living in association with man, whether as domestic animals or as animals bred in the laboratory. Even when diabetes was reported in such species as the tree shrew [1] and the dolphin [2] this was in individuals living close to man and fed by him. This generalization, however, may be less meaningful than might appear, since it is not easy to know whether animals roaming wild are diabetic or not! In the only survey of a sizable population of a wild species known to us, that of the Armenian Hamster, Yerganian did observe a significant incidence of temporary glycosuria [3].

Since von MerIng and Minkowski's observation that pancreatectomy induces a diabetes-like state, and after the cardinal discovery of insulin by BANTING and BEST, with its subsequent widespread therapeutic use, it became rather generally accepted that most of what was worth knowing about the pathogenesis of diabetes was known, and work on this topic ebbed. Heralded by Houssay's, by Long and Lukens', and by Young's disclosures that the diabetic state and the sensitivity to insulin may be altered by other hormones, the last 15 years have seen a complete and drastic reevaluation of what is known about the etiology and pathogenesis of this major disorder which, sooner or later, affects at least $5 \%$ of the population of the so-called "developed" regions of the world. The result of this re-evaluation is clear: there exists no certain knowledge about the primary inherited defect in diabetes mellitus, about the mode of genetic transmission of the disease, about the number of primary defects that may be involved, about the precise relative importance of genetic and environmental factors, or about the relationship between the rather well characterized metabolic anomalies of the acute diabetic syndrome and the much less clearly understood, but all too painfully evident, major features of the chronia diabetic syndrome: microangiopathy, neuropathy and accelerated vascular aging.

Many thoughtful workers in the field of diabetes are beginning to suspect that this rather sorry state of affairs may result primarily from the complex and multiple interactions of several genetic factors with the seemingly endless variants of overall genetic background, and with the many and changing environ- mental conditions which characterize modern human existence. Accordingly, it seems eminently appropriate to attempt to obtain an entirely fresh view of the problem by making use of the occurrence in animals, and particularly in small laboratory animals, of syndromes that exhibit many if not all of the features of human diabetes. In these animals we have populations where both the genetic and the physical environment can be controlled, and it is not unreasonable to hope that they may help us to unravel some of the components that are likely to be needed before we can understand human diabetic pathogenesis. Indeed, when we consider the immense advantages which microbiology has derived from an understanding and successful use of spontaneous mutations, it is difficult to understand why such a relatively small amount of effort has as yet been spent upon a similar approach to mammalian metabolism in general, and to the genesis of mammalian diseases in particular.

of course, there have been major pioneers and pioneering institutions, such as the Jackson Memorial Laboratories, in Maine, or the laboratories in New Zealand that have been devoted by BIELschowsky and BTELschowsky to the segregation of certain genetic characteristics of mice. As a result of their efforts, and of the efforts favoured by serendipity of several curious observers, we can already compile a list of 13 mutations, inbred strains, and species lines that exhibit a tendency for the development of diabetes (Table 1). This listing, established in collaboration with all the participants in this workshop, and particulary with the help of Dr. Margarex DICkIE from the Jackson Memorial Laboratories, should serve the purpose of defining gene symbols and recommending names of strains and species; it also recalls previously used synonyms, which may have led to some confusion in the recent past. In addition, and perhaps more importantly, the table should serve to emphasize that, among the animals that have already been shown to exhibit some of the traits of diabetes, there are single gene mutations, dominant or recessive modes of transmission, inbred strains, $F_{1}$ hybrids that exhibit a higher incidence of diabetes than either parent strain, and species lines where either the genetic background, or the environmental conditions may play a major role in uncovering the predisposition to a diabetes-like state. Unless we assume that man is much simpler than the mouse, it would surely seem indicated to investigate in greater detail all of the animals in this table in order to see if we can discover the basic lesion(s) of diabetes.

The knowledge of ignorance is said to be the beginning of wisdom, and acknowledged ignorance 
Table 1. Types of inherited "diabetes" in mus musculus and in other small laboratory rodents ${ }^{3}$

\section{Mus musculus}

A. Single gene mutations

\begin{tabular}{llll}
\hline Gene Symbol & Gene Name & Existing Stocks & Synonyms previously used but not now recommended \\
\hline $\mathrm{A}^{\mathrm{y}}$ & yellow or lethal yellow & many & obese yellow, yellow obese \\
$\mathrm{A}^{\mathrm{vy}}$ & viable yellow & $\mathrm{C} 57 \mathrm{BL} / 6 \mathrm{~J}-A^{\text {vy }}$ & - \\
$\mathrm{A}^{\text {iy }}$ & intermediate yellow & $\mathrm{C} 57 \mathrm{BL} / 6 \mathrm{~J}-A^{i y}$ & - \\
$o b$ & obese & $\mathrm{C} 57 \mathrm{BL} / 6 \mathrm{~J}-o b$ & AO, obese hyperglycemic, \\
& & & North American obese hyperglycemic, etc. \\
$a d$ & adipose & - & adipose - Edinburgh \\
$d b$ & diabetes & $\mathrm{C} 57 \mathrm{BL} / \mathrm{KsJ}-d b$ & -
\end{tabular}

B. Inbred strains and $\mathrm{F}_{1}$ hybrids

\begin{tabular}{lll}
\hline Recommended name & Synonym & Synonyms previously used but not now recommended \\
\hline NZO & New Zealand obese & - \\
KK & KK mouse & Japanese obese \\
C3Hf $\times$ I F & C3fI F & Wellesley mouse
\end{tabular}

\section{Other species}

Acomys cahirinus

Psammomys obesus

Spiny mouse Sand rat, desert rat Chinese hamster Fatties
Acomys dimidiatus

$-$

$-$

"Fatty": single mutant gene in the rat

1 Mouse News Letter, semi-annual bulletin produced and distributed by the International Committee on Laboratory Animals and the Laboratory Animals Centre, MRC Laboratories, Woodmansterne Road, Carshalton, Surrey, England.

2 Staats, J. Standardized Nomenclature for Inbred Strains of Mice. Third Listing, Cancer Res. 24, 147 (1964).

In many instances the investigator should check his source of animals and get the correct name for the strain or mutant he is using.

3 "Diabetes has not been established in all of these animals. It is suspected in all, with the possible exception of "fatties", where obesity and hyperlipemia are the predominant features.

was the motivation for this workshop, together with the hope of learning through the confrontation of a group of workers actively concerned with the study and observation of one or several types of these fascinating animals with spontaneous and genetically controlled diabetes mellitus.

\section{References}

[1] RabB, G. B., B. S. Getty, W.M. Wilitamson, and L.S. Lombard: Spontaneous diabetes mellitus in tree shrews, Urogale Everetti. Diabetes 15, 327-330(1966).

[2] KenNeY, D. W. Cited by Schweissheimer, W. Diabetes beim Delphin. Der Diabetiker 16, 48 (1966).

[3] Ymrganian, G. Mentioned at the Ciba Colloquium on Diabetes Mellitus, held in London, October 1963.

Albert E. Renold, Geneva

Wrtutam E. Dutin, Kalamazoo 